\title{
In Retrospect: Funes the Memorious
}

\section{When Rodrigo Quian Quiroga visited Jorge Luis Borges's private library, he found annotated books that bear witness to the writer's fascination for memory and neuroscience.}

\author{
Funes the Memorious \\ by Jorge Luis Borges \\ First published in book form in 1944
}

In 1944, the great Argentinean writer Jorge Luis Borges (1899-1986) published Funes the Memorious. It is the fictional story of Ireneo Funes, who, after falling off his horse and receiving a bad head injury, acquired the amazing talent - or curse - of remembering absolutely everything. "He knew the forms of the clouds in the southern sky on the morning of April 30, 1882, and he could compare them in his memory with the veins in the marbled binding of a book he had seen only once," Borges relates.

Borges is known for his fascination with mathematical and philosophical concepts, from infinity to history paths. Through Funes's story, he explores the vast labyrinths of memory and the consequences of an infinite recollection. His choice of character reveals the author's longstanding interests in psychology, memory and neuroscience.

A quest for knowledge about Borges led me to visit his widow, María Kodama, last year in Buenos Aires. Borges himself, she explained, had an exceptional memory. He could quote passages in Spanish, English, German and other languages. Borges purposely enriched his memory from an early age, knowing that he had a congenital disease that would eventually leave him blind and unable to read. Ironically, he lost his sight in 1955, the year he was appointed director of the Argentinean national library, but he retained his interest by asking others to read to him. Kodama recalled that, in one of her first meetings with the writer, he asked her to recite a specific passage in a book. To her surprise, he quickly guided her to the exact page, even though he had been blind for many years.

Characteristically modest, Borges considered himself more of an extraordinary reader than an accomplished writer. Kodama kindly showed me his private library, hosted by the Jorge Luis Borges International Foundation in Buenos Aires, which she directs. From the many annotations that adorn his personal copies of books, it is clear that his prolific reading had a great impact on his works.

For example, a copy of The Mind of Man, a psychology textbook by Gustav Spiller from 1902, contains an intriguing note by Borges: "Memories of a lifetime, page 187." On this page, Spiller estimates how many memories a person has from different stages in a lifetime: around 100 for the first 10 years, 3,600 until 20 years, 2,000 more memories between the ages of 20 and 25 , reaching about 10,000 in the first 35 years of life. He also states how much time it would take to recall these memories. For example, one does not remember every detail of a long trip, but instead certain landmark points - perhaps the moment of departure and arrival, or some stop in between. Borges says of Funes: "Two or three times he had reconstructed an entire day; he had never once erred or faltered, but each reconstruction had itself taken an entire day."

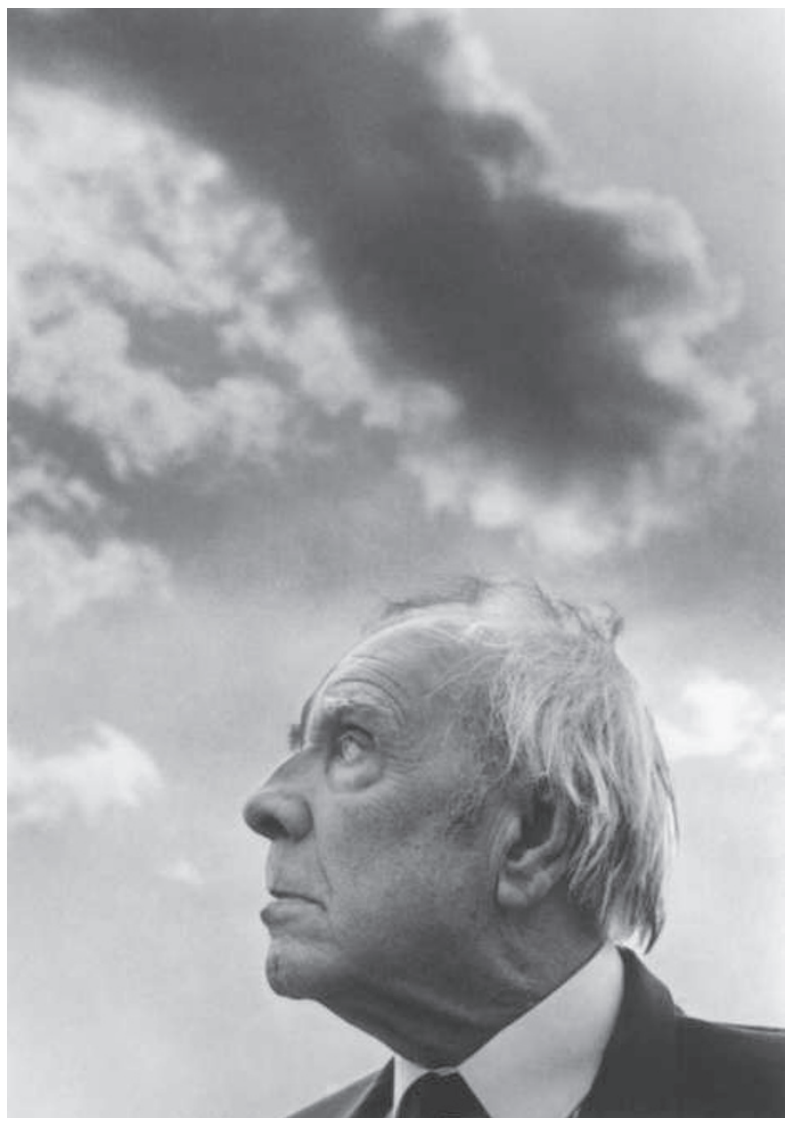

Jorge Luis Borges wrote of a protagonist who could remember everything - including the shapes of clouds on any particular day.
In the story of Funes, Borges described very precisely the problems of distorted memory capacities well before neuroscience caught up. We now know that memory function is linked to a particular brain area, the hippocampus, which lies at the end of the neural pathway that processes sensory information. Much of this knowledge came from the study of Patient H. M., who, in the 1950s, had his hippocampus surgically removed to cure him of epilepsy. Although he initially seemed to be normal after the surgery, it soon became apparent that he had developed anterograde amnesia: he could recall people and facts from before the surgery, but not recent events.

Evidence from Patient H. M. suggests that the hippocampus is crucial for the formation of new memories. In a study using electrodes to probe this brain region in epileptic patients for clinical reasons, we identified a type of neuron that fires in response to particular abstract concepts (R. Quian Quiroga et al. Nature 435, 1102-1107; 2005). For example, one neuron in a patient fired only in recognition of different pictures of the actress Jennifer Aniston; another responded only to images of another celebrity, Halle Berry. It is thus possible that these neurons link perception and memory by creating the abstract encoding we use to store memories - especially considering that we tend to remember concepts and forget irrelevant details. If these neurons are lacking, the ability to generate abstractions may be limited, leading to pathologies such as autism or characters like Funes.

Even without this scientific knowledge, Borges's intuitive description is sharp: Funes, he wrote, was "virtually incapable of general, platonic ideas... His own face in the mirror, his own hands, surprised him every time he saw them ... To think is to ignore (or forget) differences, to generalize, to abstract. In the teeming world of Ireneo Funes there was nothing but particulars."

Rodrigo Quian Quiroga is professor and head of bioengineering in the Department of Engineering at the University of Leicester, Leicester LE1 7RH, UK. e-mail: rqqg1@leicester.ac.uk 